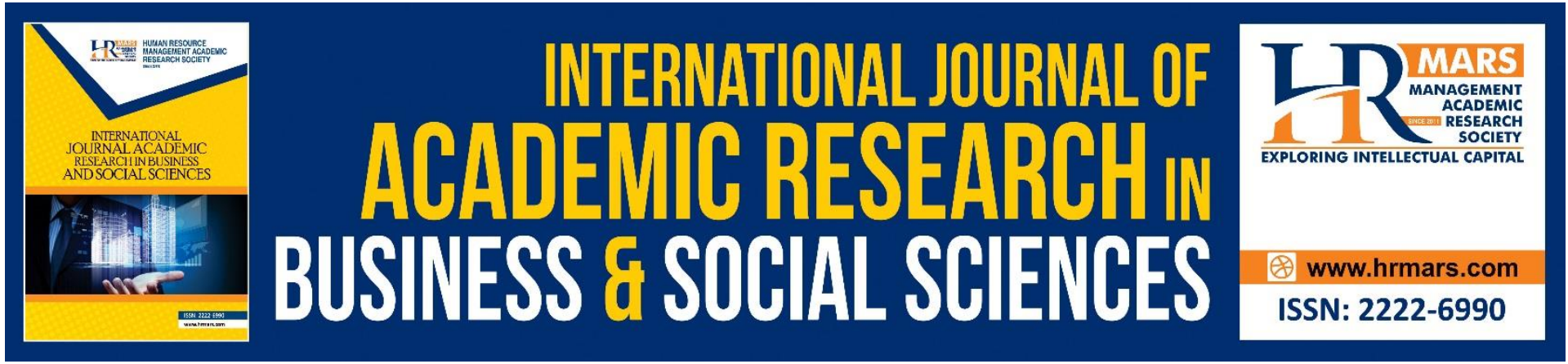

\title{
Production of English Vowel by Libyan EFL learners: Insights from Unnormalized and Normalized Data
}

Kalthoum Ramadan, Yap Ngee Thai

To Link this Article: http://dx.doi.org/10.6007/IJARBSS/v11-i7/10377

DOI:10.6007/IJARBSS/v11-i7/10377

Received: 25 May 2021, Revised: 29 June 2021, Accepted: 18 July 2021

Published Online: 30 July 2021

In-Text Citation: (Ramadan \& Thai, 2021)

To Cite this Article: Ramadan, K., \& Thai, Y. N. (2021). Production of English Vowel by Libyan EFL learners: Insights from Unnormalized and Normalized Data. International Journal of Academic Research in Business and Social Sciences, 11(7), 1586-1603.

Copyright: (c) 2021 The Author(s)

Published by Human Resource Management Academic Research Society (www.hrmars.com)

This article is published under the Creative Commons Attribution (CC BY 4.0) license. Anyone may reproduce, distribute, translate and create derivative works of this article (for both commercial and non-commercial purposes), subject to full attribution to the original publication and authors. The full terms of this license may be seen at: http://creativecommons.org/licences/by/4.0/legalcode

Vol. 11, No. 7, 2021, Pg. 1586 - 1603

http://hrmars.com/index.php/pages/detail/IJARBSS

JOURNAL HOMEPAGE

Full Terms \& Conditions of access and use can be found at http://hrmars.com/index.php/pages/detail/publication-ethics 


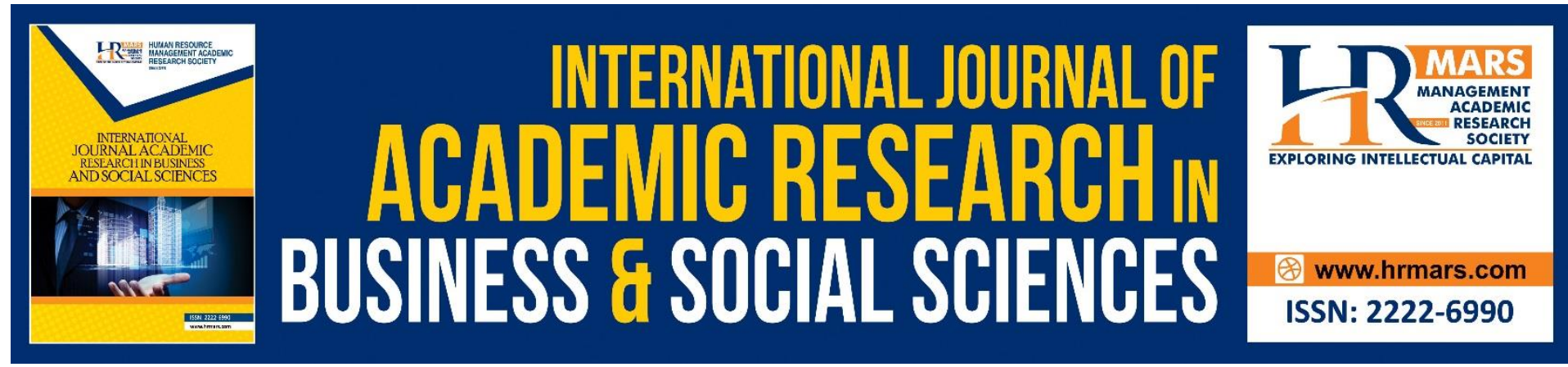

\title{
Production of English Vowel by Libyan EFL learners: Insights from Unnormalized and Normalized Data
}

\author{
Kalthoum Ramadan ${ }^{1}$, Yap Ngee Thai ${ }^{2}$ \\ ${ }^{1}$ Department of English, Faculty of Arts, University of Al-Jabal Al-Gharbi, Yefren, Libya, \\ ${ }^{2}$ Department of English, Faculty of Modern Languages and Communication, Universiti Putra \\ Malaysia, 43400 Serdang, Selangor, Malaysia \\ Email: kalthoum66@yahoo.com,ntyap@upm.edu.my
}

\begin{abstract}
Previous studies have established that male and female speakers differ in their production of foreign language (FL) vowels due to biological differences in the vocal tract. These differences present a challenge when subjects recruited for an instrumental analysis of speech sounds include speakers of both genders. Most previous studies, therefore, focus on only one gender to avoid the problem of biological differences between males and females. However, different gender groups may perform differently in speaking tasks as their language experience may be influenced by other social factors. Therefore, the aim of this study is to assess the differences between Libyan male and female speakers in the production of English vowels, by examining the data with and without the use of normalization to determine the most difficult English vowels for Libyan male and female speakers. To achieve this goal, seventy Libyan participants (35 male and 35 female) were recruited to perform a speech production task of eleven English vowels embedded in carrier sentences. The data were collected and analyzed using PRAAT to extract the F1 and F2 formant frequencies for each vowel and to calculate the Euclidean distance (ED) of the English vowels produced by using the centroid as the reference point. With the unnormalized data, more overlaps were found for the male speakers when compared to the female speakers as the vowel space were more centred for the males compared to the females. With the unnormalized data, different pairs of vowel contrasts were identified as potentially problematic. However, with the normalized data, better categorical distinction is found in general. Only three vowels emerged as potentially problematic as the other pairs could potentially be disambiguated using vowel duration as a cue. The study demonstrated the utility of the Lobanov method for normalizing speech data to reduce variability associated to gender differences. The efficacy of the Lobanov method of normalization remains to be tested further to verify if the predictions made about difficult vowel pairs for Libyan EFL learners are indeed attested in their discrimination of these vowel pairs in future research.
\end{abstract}

Keywords: Spectral Measurements (F1 And F2), Gender, Libyan Learners of English, Normalization. 


\section{Introduction}

Language is a powerful tool in human communication. It helps people to express their ideas and feelings easily and successfully. The language used for communication can be either their first language, which is acquired in the first years of life, or it can be another language that is acquired later during their life span. Nowadays, adults usually learn another language, and English as a second or a foreign language is a popular choice. For example, Arab speakers often choose to acquire English as a foreign language (EFL) as it is an international language and is very commonly used in social media and technology. English is also often used to discuss political issues that are of interest to the international community (Walker, 2010). Therefore, Arab EFL learners may try to master the language to the level as near native-like as possible to communicate with other speakers of English and to keep in touch with the globalization movements around the world.

Learning English as a foreign language (EFL) is known to be very challenging for most EFL learners. They need to master many essential skills, including listening and speaking skills that play an important role in the communication process. Fraser (2010) stated that while these skills are the most challenging skills for many learners, they are, at the same time, the most important skills the learners aim to master. English and Arabic differ in their vowel inventories. While English has eleven vowels, most varieties of Arabic have at least six vowels. Therefore, English vowels that do not exist in Arabic dialects tend to be very challenging for Arab learners (e.g. Almbark, 2012; Khalil, 2014). However, as argued by Flege (1995), even when the vowels do exist in both languages, if they are produced or perceived as members of a different $L 1$ vowel category than the intended English vowel category, misinterpretation can still occur. The production of English vowels as L1 vowels may still lead to misinterpretation as some spectral shift, which is acceptable in the L1 may result in categorical shifts in the L2 that may affect the intelligibility of the speakers of non-native varieties of English.

According to the Education First's (EF) English Proficiency Index (2019), most Arab speakers ranked between low to extremely low in their English skills, including pronunciation. Many Arab EFL learners have the goal to speak English in an intelligible manner as it is the language of global economic and culture development. To be intelligible, they need to pronounce English sounds accurately, particularly English vowels as the vowel forms the core syllable of any English word. Learners who struggle with acquiring English sounds, particularly English vowels may encounter serious communication problems and they may perform poorly in extended discussions (Pathan, Aldersi, \& Alsout, 2014; Emran \& LB, 2017). For example, it was found that Arab learners usually replace some English vowels with another vowel, which can cause embarrassment for the speaker, difficulties for the receiver to comprehend them as these substitutions may result in a change of the meaning in the message delivered. Arab learners often confuse the following vowel contrasts: /e/ versus /I/, /o/ versus / /, and /a:/ versus /æ/ (Setyaningsih, Wijayanto, \& Suparno, 2019). Thus, the words containing these vowels are produced and perceived incorrectly, such as in /tan/ is produced and perceived as/tIn/, /hat/ as /hot/, and / ka:t/ as / kært/. These problems not only affect individual sounds but can affect comprehension of the whole conversation. 


\section{Literature Review \\ Gender Differences in the Production of English Vowels}

There are several factors that affect the accuracy in learning speaking skills, particularly the production of English vowels. One of these factors is the gender of the learner. Many studies reported that males differ from females in their production of English vowels. Hunter and Yarkiner (2014) analysed the production of English vowels when produced by 4 female and 2 male Turkish speakers. The results revealed variation between males and females in the production of English vowels. These differences led to separate description of difficult English vowels for Turkish male and female speakers. Sulong (2016) compared the production of English vowels and Malay vowels produced by 120 Malay male and female speakers from three different Malay dialects. The results of the spectral measurements (F1 and F2) for males and females were presented and discussed separately, indicating that there are differences between male and female speakers in the production of Malay and English vowels. Atanda, Yusof, and Husni, (2017) further provided statistical analysis of English vowels produced by Nigerian speakers of English. In presenting and discussing the results, the authors also compared male and female speakers separately as there are differences in the acoustic measurements of the vowels under study.

Similarly, Abbasi et al (2018) also analyzed the acoustic properties of five English vowels: /I/, $/ æ /, / \varepsilon /, / \mathrm{b} /$, and $/ \partial /$ produced by Pakistani English learners. Five males and five females produced 500 voice samples of minimal pairs that contrasted these vowels. The results revealed that male Pakistani speakers differed from female speakers in the production of English vowels. Koffi (2019) also presented the acoustic measurements of English vowels by Nepali male and female speakers separately, pointing out that there are physiological differences between the two genders in the laryngeal anatomies. From the review of past studies, there were none to our knowledge that have examined the differences between Libyan male and female EFL learners in terms of their production of English vowels.

\section{Vowel Normalization}

Normalization refers to the process by which differences among vowels of the same category are reduced. A big problem faced by researchers in socio-phonetic variation is that no two speakers' vocal tracts possess similar dimensions. Consequently, there will be phonetic differences in the production of the same phoneme resulting from physiological differences in the vocal tract of the speakers. It has been recognized that the raw Hertz formant frequencies of various speakers cannot be compared, and that it is not appropriate to plot formant values in Hertz from various speakers on the same formant chart (Watt, Fabricius \& Kendall, 2010). This is a problem for socio-phonetic research which endeavours to describe variation and change by comparing speech from various speakers. The solution is, in principle, to eliminate as much as possible of the inter-speaker formant value differences that result from these biological differences. This would leave quantities unaffected by the size of a speakers' vocal tract that would be acceptable for direct comparison. The process of transforming formant frequencies to make them directly comparable with those from other speakers is called Vowel Formant Normalization.

Some researchers may place greater emphasis on one criterion over the others. This largely depends on the nature of the study. For instance, perception-based studies want normalisation to approximate the process of human vowel perception as closely as possible 
(Rosner, 1994; Syrdal \& Gopal, 1986), while socio-phonetic studies are less inclined towards this, but place greater emphasis on the maintenance of socio-phonetically relevant information, such as age-based variation (Fabricius, 2008; Watt et al., 2010; Langstrof, 2006; Thomas \& Kendall, 2007). Different approaches may also be adopted depending on the variation from the data elicited. For example, the studies may elicit data from natural speech context where the types of words with the target vowels may differ across subjects, or the data may be extracted from a natural speech corpus (Fabricius, 2008; Fabricius, Watt, \& Johnson, 2009).

Normalization procedures have traditionally been categorised according to whether they are vowel intrinsic or extrinsic, formant intrinsic or extrinsic, speaker intrinsic or extrinsic, or a combination of these six categories (Adank, 2003; Adank, Smits, \& van Hout, 2004; Thomas \& Kendall, 2007; Clopper, 2009; Fabricius et al., 2009; Watt et al., 2010). Vowel-intrinsic techniques use information from a single vowel token, while vowel-extrinsic techniques use information from multiple vowels, frequently across numerous vowel categories to normalise a formant value. Formant-intrinsic procedures normalise formant value utilising information from occurrences of that formant only, employing F1 measurements to normalise an F1 value, for instance, while formant-extrinsic procedures use information from multiple formants, for example, using F1, F2 and F3 measurements to normalise an F1 value. Speaker-intrinsic methods use information from a single speaker, while speaker-extrinsic methods use information from a population of speakers.

According to Adank et al (2004); Fabricius et al (2009), who compared the efficiency of several normalisation procedures to reduce anatomical variation but preserve phonemic and dialectal information, the LOBANOV procedure succeeds in preserving interesting phonemic and sociolinguistic variation while minimizing anatomical variation. LOBANOV is a speaker intrinsic and vowel extrinsic procedure. It is based on the calculation of the Z-score transformation for the formant frequencies using an online software package NORM (Thomas \& Kendall, 2007), which implements the z-score formula. It is the best method to factor out physiological differences within-participant groups (Adank et al., 2004; Pereira, 2014). Hence, the LOBANOV procedure is used in this study as it is considered as the best method that preserves interesting phonemic and sociolinguistic variation while minimizing anatomical variation across speakers (Adank et al., 2004).

\section{Objectives of the Study}

This study aims to achieve the following objectives:

1. To assess the differences between male and female Libyan EFL learners in the production of English vowels using unnormalized formant frequencies

2. To compare the analysis of unnormalized and normalized analysis to identify potentially challenging pairs of vowel contrasts for male and female Libyan EFL learners.

\section{Methods and Material Research Design}

This study is a non-experimental study, which employs the quantitative method to instrumentally analyse the English vowels produced by Libyan EFL learners. It measures the acoustic information of English vowels and the acoustic distance between these vowels to 
determine possible vowel contrasts that may be challenging to distinguish and may potentially affect speech intelligibility.

\section{Sampling Method and Participants}

The purposive sampling method was used to recruit desirable participants. The rationale for using this sampling method is that it focuses on specific characteristics of a population that are of interest to answer the research questions (Rai \& Thapa, 2004). In addition, Ritchie, Lewis, Nicholls, and Ormston (2013) indicated that purposive sampling is appropriate for studies that involve in-depth and detailed exploration of the important issues to be studied.

The sample of the study consists of 35 male and 35 female Libyan learners of English. The age of the participants ranged between 23 and 42 years. The participants reported not having any speaking or hearing impairment. All of them were native speakers of Tripoli Libyan Arabic. To ensure that the group effect was homogenous (Chladkova \& Jonas Podlipsky, 2011; Escudero \& Williams, 2012), the participants from the western part of Libya i.e. Tripoli and its surroundings were selected. All participants in this study were born, grew up, and educated in Tripoli (capital of Libya) and its suburbs. The participants were mainly recruited through personal contact.

\section{Speech Production Task}

The task involved recording sentences that contained words with the eleven target English vowels: /i:/, /I/, /e/, /æ/, /3:/, / /, /a:/, /p/, /Ј:/, / /, and /u:/. Table 1 presents the list of carrier sentences used. Unlike other productions studies that have used the same phonetic frame with the same initial and final consonant sounds (Bello, Yap, Chan, \& Nimehchisalem, 2020a; 2020b; Abdullahi, Thai, Rashid, \& Nimehchisalem, 2019), this study adopted a different set of words, as the study is part of a larger study that also examines vowel assimilation with L1 vowels (Ramadan, 2021). The words were selected based on existing words in Arabic that matched English words with the corresponding phone.

Table 1 The English stimuli used in the English production task

\begin{tabular}{ll}
\hline The vowel & The carrier sentence \\
\hline $\mathrm{i}:$ & Say "seed" again. \\
I & Say "miss" again. \\
e & Say "head" again. \\
$æ$ & Say "sad" again. \\
$3:$ & Say "shirk" again. \\
$\wedge$ & Say "shut" again. \\
a: & Say "park" again. \\
p & Say "hot" again. \\
J: & Say "short" again. \\
v & Say "shook" again. \\
u: & Say "cool" again. \\
\hline
\end{tabular}

The participants recorded the sentences in a quiet room using a Logitech headset with a builtin noise-cancellation microphone which is connected directly to the laptop via a USB port. All recordings were made using PRAAT version 6.0.37 (Boersma \& Weenink, 2018) and to ensure a high quality of recording, the sampling frequency was set to $22050 \mathrm{~Hz}$. 


\section{Data Analysis Methods}

\section{Segmentation and Acoustic Measurements of Vowels}

The recordings from each participant were saved as digital sound files and labelled individually for easy access. Each participant produced three repetitions of the eleven target English vowels resulting in 33 tokens for each participant. As there were a total of 70 participants, the total number of tokens analysed were 2310. For this study, the first two formant frequencies, F1 and F2 were extracted using the available formant tracks, which were generated using the Burg algorithm in PRAAT. The starting point of each vowel was identified manually by marking the endpoint of the consonant as the start of the periodic waveform, while the endpoint of the vowel was identified as the end of the periodic waveform and the starting point of the final consonant. Since all target words were CVC syllables, there was only one vowel in each target word.

However, to establish the steady state of the vowels, the F1 and F2 values were extracted from the midpoint of the vowel as it is considered the steady state of the vowel (Harrington, Palethorpe, \& Watson, 2000; Ladefoged, 2003; Bello et al., 2020b). After extracting the F1 and F2 values, the LOBANOV normalization method (Flynn, 2011) was used to normalize the formant values obtained. Figure 1 explains the procedure involved in the analysis of the target vowels in this study.

Open PRAAT to view the wav file and then create the Textgrid file for the individual words and vowels

Tier 1 for the orthographic transcription of the word (e.g. ten) and Tier 2 for the phonetic transcription of the vowel sound (e.g. /e/)

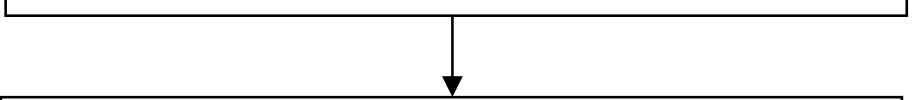

First: Run PRAAT script to extract the midpoint of F1 and F2 and were transferred to the Excel file

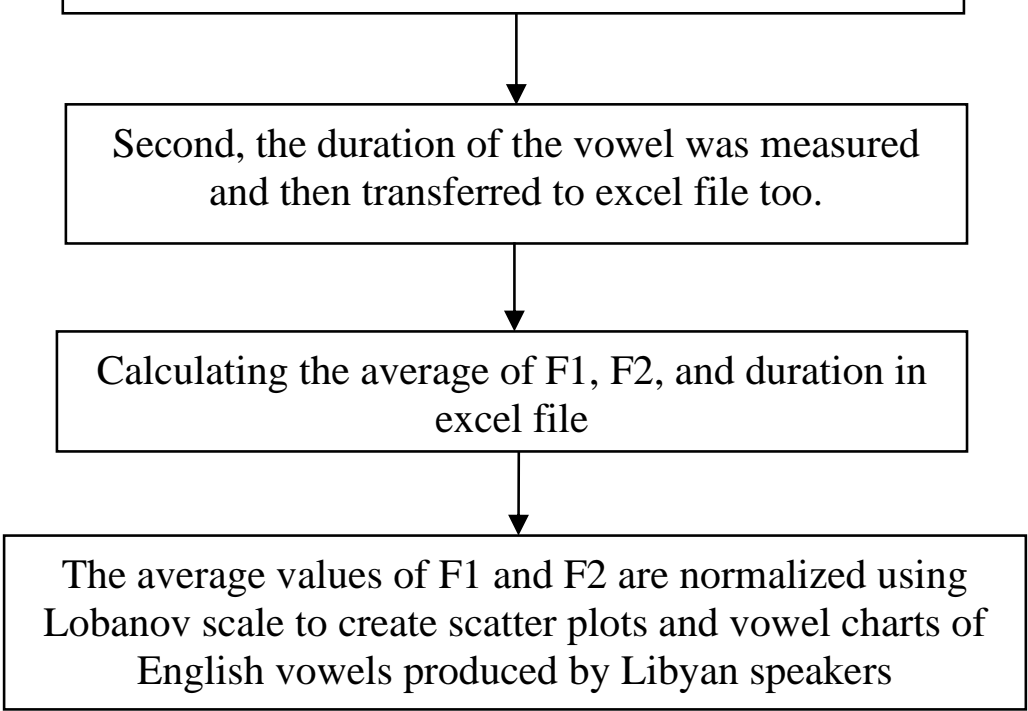

Figure 1: Procedure involved in the acoustic measurements of target vowels 
As can be seen from Figure 1, the target words and vowels were viewed and annotated using Textgrid in PRAAT. In the Textgrid, Tier 1 was created for the orthographical transcription of the words, while Tier 2 was created to record the phonetic transcription of the target vowel in English, as shown in Figure 2.

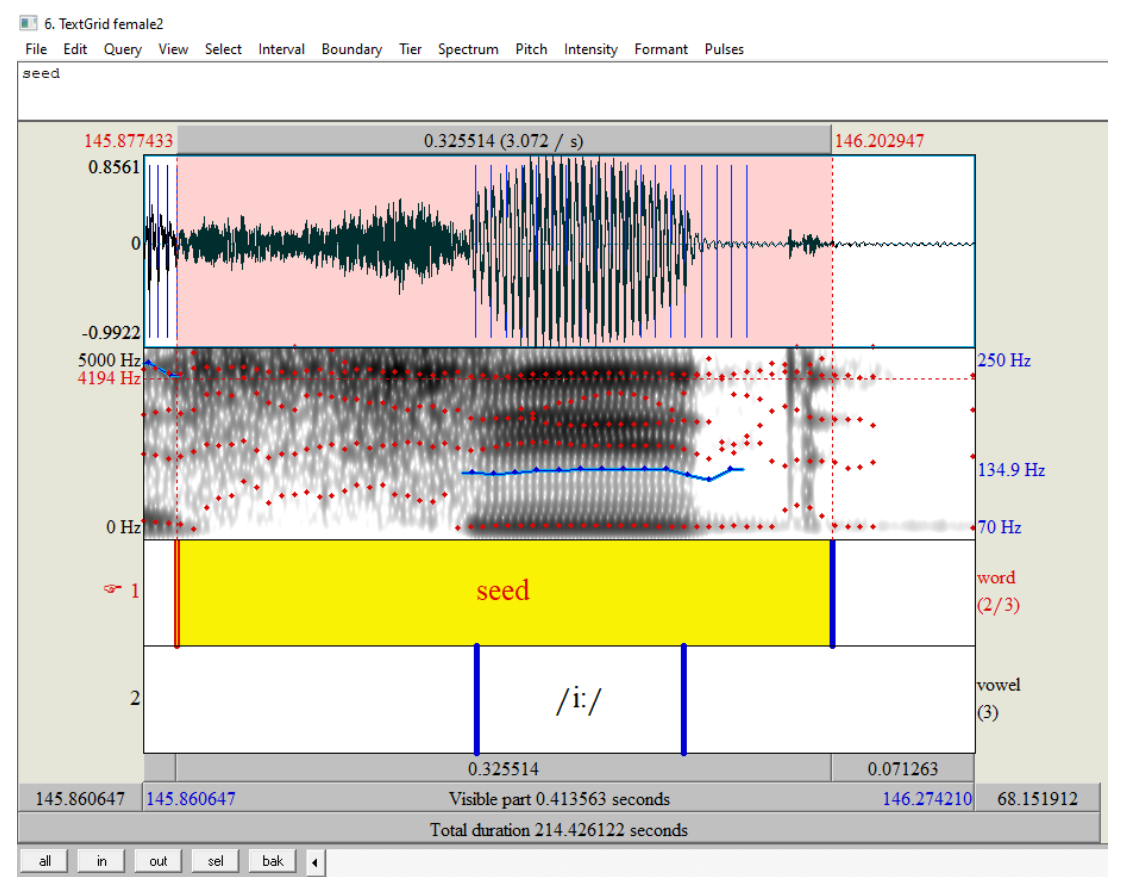

Figure 2: Annotation using Textgrid in PRAAT for the vowel /i:/ in <seed >

This step helps to divide the signals into intervals for the corresponding words and vowels for easy access when necessary. The F1 and F2 values were extracted for each target vowel using the menu commands in PRAAT as shown in Figure 3.

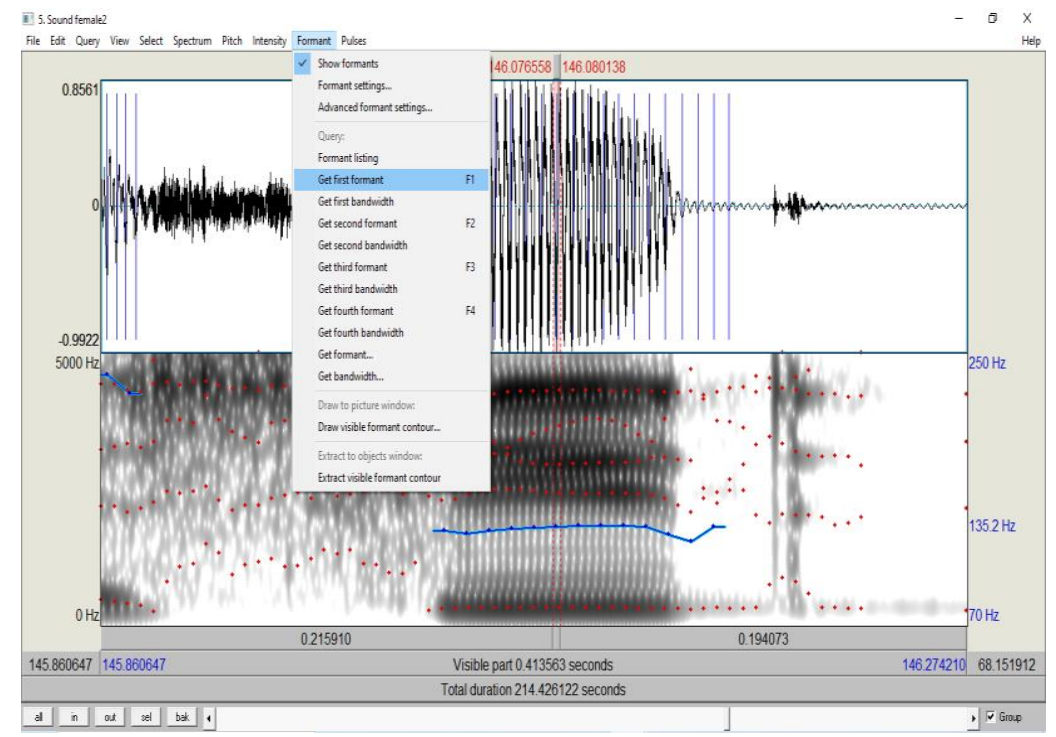

Figure 3: Waveform and spectrogram of the vowel /i:/ in <seed>

All these measurements were performed manually. Then, these values were transferred to an Excel File to calculate the averages of F1 and F2. Finally, these values were submitted to NORM (Thomas \& Kendall, 2007) to be normalized to minimize the differences between 
genders and to provide a better visual presentation of the target vowels. Following Deterding (1997), the Euclidean distance (ED) was calculated from the centriod /3:/, which helps to determine if the vowel space of males and females is different.

\section{Statistical Data Analysis}

The collected data was analysed using descriptive statistics to get the mean and the standard deviations of the F1 and F2 of the English vowels. These measures were subjected to inferential statistics using SPSS (Version 22). Degree of agreement analysis was computed to find the relationship between the measurements done by the researcher and the trained phonetician on the vowels' measurements. The results of the Pearson correlation test revealed a high correlation between the two measurements $(r=.996, p<0.01$ for $F 1 ; r=.995$, $p<0.01$ for F2). The paired sample t-test was then applied on the unnormalized F1 and F2 formant values to test the significant differences (at .05 level of significance) between the formant values for specific vowel pairs. Observations regarding overlapping vowel categories were then recorded for each gender group. Then, the one-way ANOVA and post-hoc analysis were conducted to examine overlapping categories with the normalized F1 and F2 data. Observations made were then compared from the analysis of the normalized and unnormalized data.

\section{Results}

The mean of the unnormalized F1 and F2 formant frequencies and the EDs for the eleven English vowels by Libyan males and females are shown in Table 2 and Table 3. The average values were plotted into the Bark scale and are used to plot the vowel space charts. Figure 4 presents the separate vowel space plots based on unnormalized formant frequency data produced by male and female speakers. The average ED for the male speakers is 2.18 , while the average for female speakers is 2.15 .

Table 2. The mean values for unnormalized F1 and F2 formants of English vowels for male subjects

\begin{tabular}{|c|c|c|c|c|c|c|c|}
\hline \multirow{3}{*}{ vowel } & \multicolumn{7}{|c|}{ Libyan Males } \\
\hline & \multicolumn{2}{|r|}{ F1 } & \multicolumn{2}{|c|}{ F2 } & \multirow{2}{*}{$\begin{array}{l}\text { Mean F1 } \\
\text { (Bark) }\end{array}$} & \multirow{2}{*}{$\begin{array}{c}\text { Mean F2 } \\
\text { (Bark) }\end{array}$} & \multirow[t]{2}{*}{ ED } \\
\hline & $\begin{array}{l}\text { Mean } \\
(\mathrm{Hz})\end{array}$ & $S D(\mathrm{~Hz})$ & $\begin{array}{l}\text { Mean } \\
(\mathrm{Hz})\end{array}$ & $S D(\mathrm{~Hz})$ & & & \\
\hline i: & 297 & 23.86 & 2378 & 69.65 & 2.891 & 14.201 & 3.54 \\
\hline $\mathbf{I}$ & 420 & 34.26 & 1906 & 136 & 4.028 & 12.791 & 1.77 \\
\hline e & 450 & 78.01 & 1970 & 145 & 4.296 & 13.006 & 1.88 \\
\hline$æ$ & 532 & 69.92 & 1708 & 129 & 5.013 & 12.068 & 0.944 \\
\hline 3: & 499 & 99.79 & 1493 & 152 & 4.728 & 11.168 & 0 \\
\hline$\Lambda$ & 599 & 50.90 & 1333 & 93.94 & 5.576 & 10.405 & 1.14 \\
\hline D & 541 & 52.35 & 1144 & 95.13 & 5.089 & 9.385 & 1.82 \\
\hline a: & 654 & 38.37 & 1209 & 79.37 & 6.023 & 9.751 & 1.92 \\
\hline ग: & 483 & 74.50 & 1018 & 321 & 4.588 & 8.625 & 2.54 \\
\hline v & 579 & 140 & 1522 & 776 & 4.050 & 8.456 & 2.79 \\
\hline u: & 390 & 53.07 & 826 & 210 & 3.755 & 7.330 & 3.96 \\
\hline
\end{tabular}


INTERNATIONAL JOURNAL OF ACADEMIC RESEARCH IN BUSINESS AND SOCIAL SCIENCES Vol. 11, No. 7, 2021, E-ISSN: 2222-6990 @ 2021 HRMARS

Table 3 The mean values for unnormalized F1 and F2 formants of English vowels for female subjects

\begin{tabular}{|c|c|c|c|c|c|c|c|}
\hline \multirow{3}{*}{ vowel } & \multicolumn{7}{|c|}{ Libyan Females } \\
\hline & \multicolumn{2}{|l|}{ F1 } & \multicolumn{2}{|l|}{ F2 } & \multirow{2}{*}{$\begin{array}{l}\text { Mean F1 } \\
\text { (Bark) }\end{array}$} & \multirow{2}{*}{$\begin{array}{l}\text { Mean F2 } \\
\text { (Bark) }\end{array}$} & \multirow[t]{2}{*}{ ED } \\
\hline & $\begin{array}{l}\text { Mean } \\
(\mathrm{Hz})\end{array}$ & $S D(\mathrm{~Hz})$ & $\begin{array}{l}\text { Mean } \\
(\mathrm{Hz})\end{array}$ & $S D(\mathrm{~Hz})$ & & & \\
\hline i: & 375 & 34.9 & 2507 & 193.24 & 3.618 & 14.527 & 3.74 \\
\hline $\mathbf{I}$ & 511 & 61.93 & 2004 & 397.30 & 4.832 & 13.117 & 1.98 \\
\hline e & 570 & 98.39 & 2192 & 465.9 & 5.335 & 13.691 & 2.501 \\
\hline$æ$ & 810 & 69.39 & 1822 & 245.01 & 7.214 & 12.496 & 2.30 \\
\hline 3: & 568 & 22.11 & 1498 & 166.96 & 5.318 & 11.190 & 0 \\
\hline$\Lambda$ & 692 & 57.87 & 1551 & 161.77 & 6.324 & 11.424 & 1.03 \\
\hline D & 676 & 97.59 & 1371 & 193.02 & 6.198 & 10.594 & 1.06 \\
\hline a: & 856 & 57.05 & 1504 & 106.39 & 7.543 & 11.217 & 2.22 \\
\hline ग: & 624 & 41.13 & 1149 & 90.18 & 5.781 & 9.414 & 1.83 \\
\hline $\boldsymbol{v}$ & 568 & 27.09 & 1231 & 178.8 & 5.318 & 9.872 & 1.33 \\
\hline u: & 522 & 75.40 & 873 & 246.87 & 4.927 & 7.663 & 3.54 \\
\hline
\end{tabular}
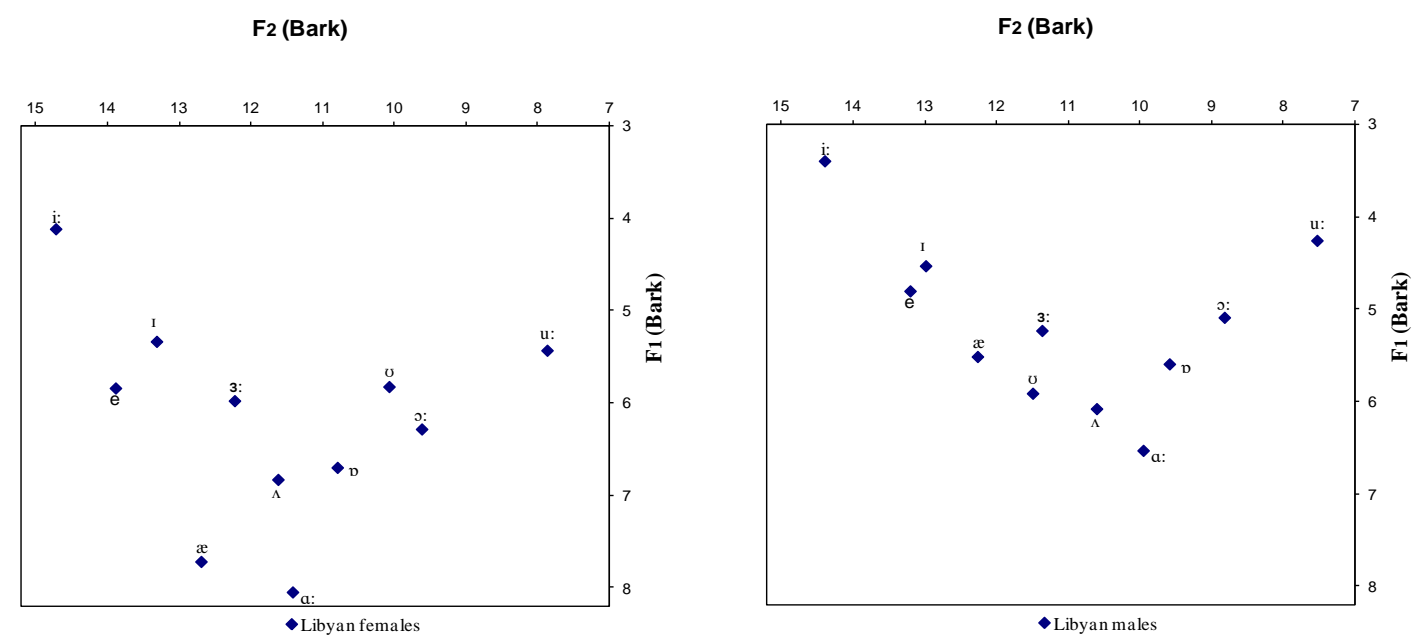

Figure 4: Formant plots of unnormalized data for English vowels by Libyan male and female EFL learners

A close examination of these plots reveals that the vowel space of English vowels by male speakers seems to be more compact resulting in more overlaps between adjacent vowel phonemes compared to that of female speakers. The English vowel space for female Libyan EFL speakers seems to be more spread out, which may predict better phonemic discrimination between these vowel categories. To verify these observations, the paired sample $t$-test was conducted with specific pairs of vowel contrasts to identify overlaps between the F1 and F2 values for the female subjects and the male subjects. Table 4 presents the summary of the results. Most of the formant values are significantly different. The cases shaded in grey indicate instances where the difference is not statistically significant, and these are the cases in which categorical overlap are predicted. As shown in Table 4, there are more cases of overlap found in the male subjects compared to the female subjects. Another observation found is the overlaps involve different vowel pairs in both groups of subjects. For example, for the vowel pair /æ-3:/, no significant difference was found in the F1 values for the male 
participants suggesting an overlap in terms of vowel height, but for the female subjects the overlap is found in the F2 values suggesting an overlap in terms of frontness. Also, both F1 and $\mathrm{F} 2$ formants overlapped for the vowel pair $/ \Lambda-\mho /$, however, the contrast was maintained for the female speakers. The results confirm the need to present a separate analysis for male and female participants with unnormalized data as the conclusions drawn using the unnormalized data are not necessarily the same. However, it may be more meaningful to try to generalize the results across gender groups to provide a unified recommendation for teaching and learning .

Table 4. Paired sample $t$-test for vowel contrasts for Libyan EFL learners using unnormalized data

\begin{tabular}{|c|c|c|c|c|c|c|c|c|}
\hline \multirow{3}{*}{$\begin{array}{c}\text { Vowel } \\
\text { contrasts }\end{array}$} & \multicolumn{4}{|c|}{ Male } & \multicolumn{4}{|c|}{ Female } \\
\hline & \multicolumn{2}{|l|}{ F1 } & \multicolumn{2}{|l|}{$\mathrm{F} 2$} & \multicolumn{2}{|c|}{ F1 } & \multicolumn{2}{|c|}{$\mathrm{F} 2$} \\
\hline & $t(\mathrm{df})$ & $p$ & $t(\mathrm{df})$ & $p$ & $t(\mathrm{df})$ & $p$ & $t(\mathrm{df})$ & $p$ \\
\hline i: - I & $17.62(34)$ & .001 & $23.43(34)$ & .001 & $10.17(34)$ & .001 & $-6.90(34)$ & .001 \\
\hline $\mathrm{I}-\mathrm{e}$ & $-2.20(34)$ & .040 & $-2.89(34)$ & .001 & $-2.98(34)$ & .001 & $-2.30(34)$ & .030 \\
\hline e - æ & $-4.52(34)$ & .001 & $7.07(34)$ & .001 & $\begin{array}{c}- \\
11.82(34)\end{array}$ & .001 & $3.7(34)$ & .001 \\
\hline$æ-3:$ & $1.67(34)$ & .100 & $6.42(34)$ & .001 & $17.60(34)$ & .001 & $1.96(34)$ & .060 \\
\hline e - 3: & $-2.85(34)$ & .010 & $15.75(34)$ & .001 & $1.03(34)$ & .307 & $5.81(34)$ & .001 \\
\hline 3: - I & $4.99(34)$ & .001 & $14.86(34)$ & .001 & $3.07(34)$ & .001 & $4.20(34)$ & .001 \\
\hline$\wedge-3:$ & $-4.94(34)$ & .001 & $5.22(34)$ & .001 & $\begin{array}{c}- \\
11.06(34) \\
\end{array}$ & .001 & $7.17(34)$ & .001 \\
\hline$\Lambda-J:$ & $6.48(34)$ & .001 & $5.51(34)$ & .001 & $5.61(34)$ & .001 & $12.85(34)$ & .001 \\
\hline$\Lambda-v$ & $.76(34)$ & .460 & $-1.55(34)$ & .130 & $10.55(34)$ & .001 & $6.90(34)$ & .001 \\
\hline U - 3: & $-3.68(34)$ & .001 & $-.38(34)$ & .710 & $-1.55(34)$ & .130 & $14.93(34)$ & .001 \\
\hline ग: - & $-4.76(34)$ & .001 & $-3.45(34)$ & .001 & $7.13(34)$ & .001 & $-2.25(34)$ & .030 \\
\hline$v-u:$ & $7.32(34)$ & .001 & $5.2(34)$ & .001 & $3.59(34)$ & .001 & $6.74(34)$ & .001 \\
\hline $\mathrm{D}-\mathrm{J}$ & $4.37(34)$ & .001 & $2.46(34)$ & .017 & $2.78(34)$ & .001 & $6.67(34)$ & .001 \\
\hline$v-a:$ & $3.03(34)$ & .001 & $2.42(34)$ & .016 & $24.5(34)$ & .001 & $8.81(34)$ & .001 \\
\hline$\sigma-p$ & $1.67(34)$ & .110 & $2.85(34)$ & .001 & $-5.99(34)$ & .001 & $-2,73(34)$ & .001 \\
\hline$p-a:$ & $-9.85(34)$ & .001 & $-3.31(34)$ & .001 & $-8.71(34)$ & .001 & $-3.05(34)$ & .001 \\
\hline
\end{tabular}

We, therefore, used the Lobanov method to normalize the data and conducted a one-way ANOVA with full set of data to identify differences between the F1 and F2 values for all vowels. Table 5 presents the summary of the post-hoc analysis. The results show that overlap often involved only one dimension, either in terms of vowel height as indicated by the overlapping F1 formant values or frontness as indicated by the overlapping F2 formant values. We have shaded only those that would potentially result in confusion in speech production and perception as they involved adjacent vowels in the vowel space. Vowel pairs like / $\mho-I /$ that overlapped in F1 were not a concern as they are both high vowels, and an overlap in terms of $\mathrm{F} 1$ is expected. Since the $\mathrm{F} 2$ value is significantly different, good discrimination of these vowels is expected. Similarly, the overlap for F1 for the vowel pair /e - 3:/ is also expected as they are both mid vowels. 
INTERNATIONAL JOURNAL OF ACADEMIC RESEARCH IN BUSINESS AND SOCIAL SCIENCES Vol. 11, No. 7, 2021, E-ISSN: 2222-6990 @ 2021 HRMARS

Table 5. Post-hoc analysis for vowel contrasts for Libyan EFL learners using normalized data

\begin{tabular}{|c|c|c|c|c|c|c|}
\hline \multirow{2}{*}{$\begin{array}{l}\text { Vowel } \\
\text { contrasts }\end{array}$} & \multicolumn{3}{|c|}{ F1 (vowel height) } & \multicolumn{3}{|c|}{ F2 (frontness) } \\
\hline & Mean difference & Std Error & $p$ & $\begin{array}{l}\text { Mean } \\
\text { difference }\end{array}$ & $\begin{array}{l}\text { Std } \\
\text { Error }\end{array}$ & $p$ \\
\hline U-I & 9.54 & 16.48 & .56 & $578.44^{*}$ & 47.44 & .000 \\
\hline $\mathrm{I}-\mathrm{e}$ & -44.78 & 16.48 & .007 & $-126.30^{*}$ & 47.44 & .008 \\
\hline$e-æ$ & $-243.46^{*}$ & 16.67 & .000 & $316.27^{*}$ & 47.44 & .000 \\
\hline$æ-3:$ & $-228.27^{*}$ & 16.67 & .000 & $156.21^{*}$ & 47.44 & .001 \\
\hline e - 3: & 15.18 & 16.48 & .36 & $472.49^{*}$ & 47.44 & .000 \\
\hline 3: - I & $-59.97^{*}$ & 16.48 & .000 & $-346.19^{*}$ & 47.44 & .000 \\
\hline A-3: & $-120.06^{*}$ & 16.48 & .000 & $-164.24^{*}$ & 47.44 & .001 \\
\hline ^- Ј: & $92.19^{*}$ & 16.48 & .000 & $361.14^{*}$ & 47.44 & .000 \\
\hline$\Lambda-v$ & $71.97^{*}$ & 16.48 & .000 & 68.01 & 47.44 & .152 \\
\hline$v-3:$ & $-48.09^{*}$ & 16.48 & .004 & $-232.26^{*}$ & 47.44 & .000 \\
\hline ग: - & 20.21 & 16.48 & .220 & $-293.13^{*}$ & 47.44 & .000 \\
\hline$v-u:$ & $117.60^{*}$ & 16.48 & .000 & $526.96^{*}$ & 47.44 & .000 \\
\hline $\mathrm{D}-\mathrm{J}:$ & $56.02^{*}$ & 16.54 & .001 & $176.01^{*}$ & 47.61 & .000 \\
\hline$v-a:$ & $-180.19^{*}$ & 16.67 & .000 & 21.78 & 47.97 & .650 \\
\hline$\sigma-\mathrm{D}$ & $-35.81^{*}$ & 16.54 & .031 & $117.12^{*}$ & 47.61 & .014 \\
\hline $\mathrm{p}-\mathrm{a}:$ & $-144.38^{*}$ & 16.72 & .000 & $-95.34^{*}$ & 48.14 & .048 \\
\hline$æ-\Lambda$ & 25.33 & 16.48 & .13 & $320.46^{*}$ & 47.44 & .000 \\
\hline 3: - ग: & 27.87 & 16.48 & .09 & $-293.13^{*}$ & 47.44 & .000 \\
\hline
\end{tabular}

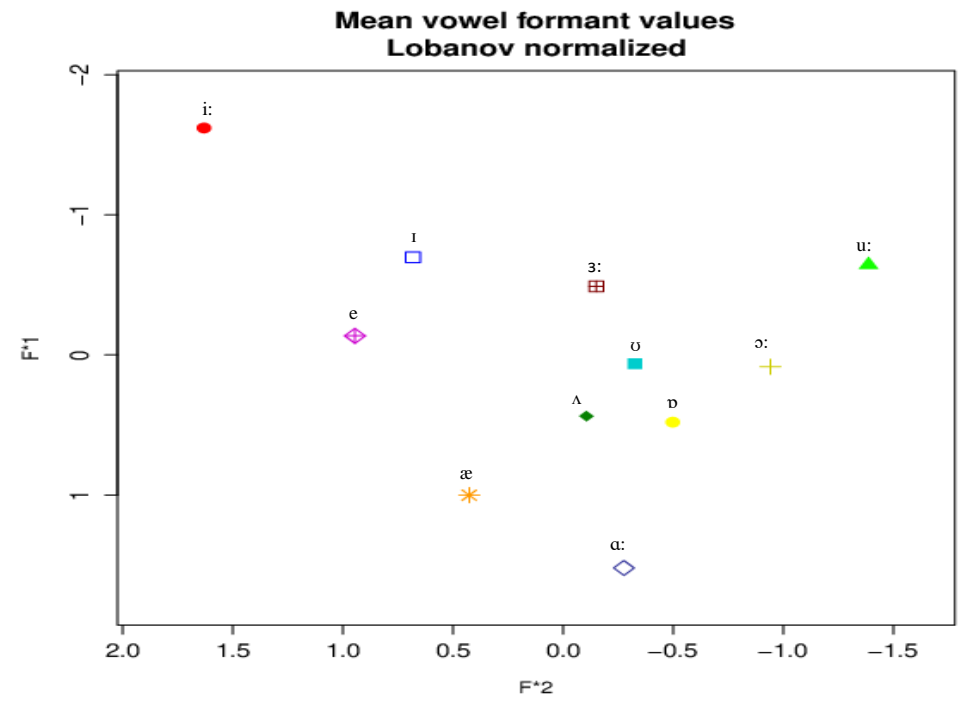

Figure 5: The normalized F1 and F2 values of all English vowels for all participants

However, what seems to be more interesting is the overlap found for F1 values for / $\mathrm{J}$ - $\mho /$ and $/ æ-\Lambda /$. These overlaps could lead to a confusion as there is an overlap between what is usually considered a high vowel/ $/$ / with the mid vowel/J:/, and an overlap between the mid vowel $/ \Lambda$ and the low vowel /æ/ unless vowel duration is used to help distinguish these categories. Similarly, the overlap for F2 values for $/ \Lambda-\mho /, / v-a: /$ and the vowel pair/p - a:/ 
suggest possible confusion in terms of frontness for these central and back vowels. As shown in Figure 5, the normalized data showed that the vowel pairs /I-e/ are located close together. However, the post-hoc tests suggest that there is good discrimination for these vowel categories. The chart also shows the proximity of $/ \mho /$ to the adjacent $/ \Lambda /$ and $/ \mathrm{p} /$. Since these are all short vowels, the distinction of these vowels needs to rely on the spectral cues and not vowel duration. Further, as the F2 values of these vowels are not significantly different, words containing these vowels are potential candidates for confusion and misinterpretation.

\section{Discussion}

Accurate pronunciation of English sounds (vowels) is considered as one of the most difficult tasks that EFL learners encounter when learning English. Past studies have reported that Arab learners of English have difficulties in learning the English vowels but since these studies involved Arabic speakers of other varieties of Arabic, the current study was designed to explore specific challenges in producing English vowels for Libyan EFL learners. The study also sought to determine the difficult vowels if the analysis involved unnormalized data for male and female learners and common vowels that may affect both groups using analysis of the normalized data.

Consistent with existing literature on differences between male and female speakers, the results revealed that there are significant differences between the F1 and F2 formant frequencies of all English when male and female sound files are analyzed. When the unnormalized data are inspected independently for each gender group, different observations were found. More pairs of vowel contrast may be affected among the male subjects as compared to the female subjects. When the normalized data is used for the analysis, the results suggest that there is good categorical distinction for most of the English vowel phonemes. Only three vowel categories were identified to be potentially difficult for Libyan EFL learners: the vowel $/ \mho /$ was too closed to $/ \Lambda /$ and $/ \mathrm{b} /$.

In general, the results from the unnormalized and normalized data show that contrasts between most vowel pairs are maintained in the production. In our study, the vowel/i:/ has the lowest F1 value and the highest F2 value, indicating that it is the higher vowel and the more fronted one compared to /I/. This indicates that the Libyan learners can successfully distinguish between the contrasts of these two high front vowels. As for the mid vowels, the analysis indicates that the Libyan EFL learners can distinguish between these contrasts and thus the contrast for mid vowels may not result in pronunciation or intelligibility problems.

The vowels that have often been reported to cause confusion among Arab EFL learners are /e/ and /I/. These results are reported in Munro (1993); Khalil (2014); Hubais and Pillai (2010). Emran and LB (2017) also found that Libyan learners replaced the /e/ with /i:/ or /I/. Ababneh (2018) also pointed out that the Saudi EFL learners confused the vowel/e/ sound with /i/. The same result was also reported by Ali (2013); Kalaldeh (2016); Al-Rubaat and Alshammari (2020). This difficulty in production may further lead to difficulty in the perception of these vowels. Al-Abdely and Yap (2016) found that one of the most difficult vowels for Iraqi Arab EFL learners to perceive is /e/. However, in both analysis involving the unnormalized and normalized data, there was a statistically significant difference for both F1 and F2 for the contrast between /e/ and /I/. The results suggest that Libyan EFL learners may not encounter the same difficulty like other Arab learners of English, possibly because the Libyan Arabic 
variety has more categories of vowel phonemes compared to other varieties of Arabic as discussed in Ramadan (2021).

Past studies with other Arab EFL learners also found that / $/$ :/ overlapped with / $\mathrm{b} /$ (Hubais \& Pillai, 2010; Haji \& Mohammed, 2019) and may cause the learners to be confused between words such as cot versus caught, and shot versus short. However, in our study, this pair of contrast was maintained in both the unnormalized and normalized data. Also, it remains unclear if the contrast between these vowel pairs would be also distinguished in terms of other phonetic cues such as vowel duration. The inconsistency between the results of this study and that of previous studies could also be attributed to the native dialect of the learners. Hubais and Pillai (2010) studied the Omani EFL learners while Haji and Mohammed (2019) examined performance of Kurdish EFL learners while we looked at Libyan EFL learners.

Nevertheless, the vowel / $\mathrm{d} /$ can be a difficult vowel as it does not exist in the Modern Standard Arabic nor in the Libyan Arabic dialect, and it was produced very close to $/ \mho /$. Mahfouz (2017) also found that Egyptian EFL learners replaced / $\mathrm{p} /$ with / $\mho /$, steering them to pronounce the word dog as $[\mathrm{d} v g]$ instead of $[\mathrm{dpg}]$. This result is also reported in Hubais and Pillai (2010), where the F1 for / $\mathrm{D} /$ and / $/$ are found to be very close. This confusion could have resulted from the influence of orthography, which is beyond the scope of this study. In our study, possible overlap was found between three vowel categories: $/ \mho /, / \Lambda /$ and $/ \mathrm{b} /$.

Haji and Mohammed (2019) found that Kurdish Iraqi learners usually pronounce $/ æ /$ as $/ \Lambda$ / like in the word family, while they pronounce /a:/ as /æ/ in words like draft and half. They assumed that those learners are attempting to shorten these vowels to adapt them to the phonetic system of their first language. Chouchane (2016) also demonstrated that Omani EFL learners are often confused with the vowels $/ æ /$ and $/ \Lambda /$, where the word catch /kæt $/$ is

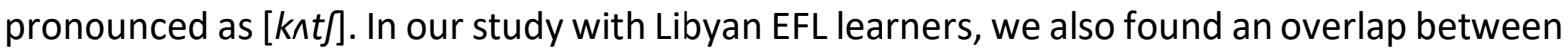
these two vowel categories for the F1 formant. Hence, it can be assumed that the /æ/ may also be a problematic vowel for the Libyan learners. This result is consistent with other studies conducted on other Arabic speakers such as (Munro, 1993; Al-Hamadi, 2012; Khalil, 2014; as well as Hubais and Pillai, 2010).

The confusion in the production of English vowels may also occur within a phonemic category. For example, Khalil (2014) stated that /u:/ and / $v /$ do not cause serious difficulties for Arab learners; however, the mid back vowel / $\mathrm{J}$ // is a problematic vowel as the results revealed that the production of Egyptians is different from the production of native English speakers. Some potential challenges that may be faced by Libyan ESL learners may be related to differences in contact with different varieties of English as various varieties of Englishes in the inner circle (Kachru, 1997) are also known to differ in terms of the inventories of their back vowels. For example, in this study, there is an overlap in the F2 formant for the vowel pair / $\mathrm{p}-\mathrm{a}$ :/. The distinction needed for this vowel pair may not be unique to EFL learners but also to native speakers of English of the different English varieties of the inner circles (Yang \& Whalen, 2015).

\section{Conclusion and Recommendations for Future Research}

This study has made a significant contribution in the field of L2 speech production by investigating the vowels produced by a group of Arab EFL learners that has been under- 
investigated. The study is considered as the first study that presents an acoustic analysis of spectral measurements of English vowels produced by Libyan EFL learners. In addition, the study has demonstrated the use of a normalization method to determine the difficult FL sounds that may affect both male and female ESL learners. The paper presented insights that may be available when the data were analyzed without and with normalization. This contribution is of great significance as it allows researchers to engage participants from both genders and not draw conclusions for both groups based on the analysis of only one group.

The findings also provide specific hypothesis to be made about possible discrimination of specific vowel pairs in a speech perception task. While the study has identified good categorical distinction in the production of most vowel pairs, it remains an empirical question whether good discrimination will also be found in a speech perception task or a speech intelligibility task. Future studies can also compare performance of male and female Libyan EFL learners to verify the efficacy of the normalization methods used in the paper to test the accuracy of the generalizations made about Libyan EFL learners.

The results from this study can be used as a useful guide to the difficulties and errors in producing and perceiving English vowels committed by Arab learners. More specifically, English teachers who teach Libyan students should realize that there are some English vowels that are more difficult than others such as $/ æ /, / \mathrm{J} /, / \mathrm{J} /, / \Lambda /, / \mathrm{p} /$ and $/ \mathrm{a}: /$, and thus help to provide targeted instructions and treatments for students to produce these vowels accurately. Students may be given plenty of opportunities to exercise the accurate pronunciation of sounds that cause difficulties, while they may not need to focus too much on sounds that have good contrast with other vowel categories such as /i:/ and /u:/.

\section{References}

Ababneh, I. (2018). English pronunciation errors made by Saudi students. European Scientific Journal, ESJ, 14(2), 244-261.

Abbasi, A. M., Channa, M. A., John, S., Memon, M. A., \& Anwar, R. (2018). An Acoustic Investigation of Pakistani and American English Vowels. International Journal of English Linguistics, 8(4).

Abdullahi, J., Thai, Y. N., Rashid, S. M., \& Nimehchisalem, V. (2019). Cross-Language perception of non-native stops and fricatives among Malay and Hausa native speakers. Journal of Language and Communication (JLC), 6(1), 307-321.

Adank, P. M. (2003). Vowel normalization. A perceptual acoustic study of Dutch vowels. PhD thesis, University of Nijmegen.

Adank, P., Smits, R., \& Van Hout, R. (2004). A comparison of vowel normalization procedures for language variation research. The Journal of the Acoustical Society of America, 116(5), 3099-3107.

Al-Abdely, A. A. W., \& Yap, N. T. (2016). Learning English vowels by Iraqi EFL learners: perceived difficulty versus actual performance. $3 \mathrm{~L}$ : Language, Linguistics, Literature $^{\circledR}, 22(1) .:$ Language, Linguistics, Literature $^{\circledR}, 22(1)$.

Al-Hamadi, H. M. (2012). Acoustic Analysis of English Pure Vowels in Clear and Conversational Speech: An Experimental Study at the University of Basra. The Arab Gulf, 40(3-4).

Ali, E. M. T. (2013). Pronunciation problems: Acoustic analysis of the English vowels produced by Sudanese learners of English. International Journal of English and Literature, 4(10), 495-507. 
Almbark, R. (2012). The perception and production of SSBE vowels by Syrian Arabic learners: The foreign language model (Doctoral dissertation, University of York).

Al-Rubaat, A. M., \& Alshammari, H. A. (2020). Analysis of Phonetic and Phonological Constraints of Saudi EFL Learners. English Language Teaching, 13(1).

Atanda, A. F., Yusof, S. M., \& Husni, H. (2017). Acoustic Analysis of Nigerian English Vowels Based on Accents. Journal of Telecommunication, Electronic and Computer Engineering (JTEC), 9(3-7), 13-20.

Bello, H., Yap, N. T., Chan, M. Y., \& Nimehchisalem, V. (2020a). Intelligibility of English vowels produced by Nigerian and Malaysian speakers, Journal of Research in Applied Linguistics, 2020, 11(2), 81-94.

Bello, H., Yap, N. T., Chan, M. Y., \& Nimehchisalem, V. (2020b). An acoustic analysis of English vowels produced by Nigerian and Malaysian ESL speakers. Journal of Language and Communication (JLC), 7(1), 561-575.

Boersma, P., \& Weenink, D. (2018). Praat: Doing phonetics by computer (Version 6.0. 37)[Computer software]. Amsterdam: Institute of Phonetic Sciences.

Chladkova, K., \& Podlipský, J. V. (2011). Native dialect matters: Perceptual assimilation of Dutch vowels by Czech listeners. The Journal of the Acoustical Society of America, 130(4), EL186-EL192.

Chouchane, A. (2016). Pronunciation difficulties for Arab learners of English. Global English Oriented Research Journal (GEORJ), 2(2), 205-2015.

Clopper, C. G. (2009). Computational methods for normalizing acoustic vowel data for talker differences. Language and Linguistics Compass, 3(6), 1430-1442.

Deterding, D. (1997). The formants of monophthong vowels in Standard Southern British English pronunciation. Journal of the International Phonetic Association, 27(1-2), 4755.

Emran, A. M., \& LB, D. A. (2017). The Errors of Segmental Phonemes among Libyans English Students Studying in Semarang City, Indonesia. Language Circle: Journal of Language and Literature, 11(2), 183-197.

Escudero, P., \& Williams, D. (2012). Native dialect influences second-language vowel perception: Peruvian versus Iberian Spanish learners of Dutch. The Journal of the Acoustical Society of America, 131(5), EL406-EL412.

Fabricius, A. H. (2008). Vowel normalisation in sociophonetics: When, why, how. Sociolinguistics Circle, Copenhagen University, September, 16.

Fabricius, A. H., Watt, D., \& Johnson, D. E. (2009). A comparison of three speaker-intrinsic vowel formant frequency normalization algorithms for sociophonetics. Language Variation and Change, 21(3), 413-435.

Flege, J. E. (1995). Second language speech learning: Theory, findings, and problems. Speech perception and linguistic experience, 233-277.

Flynn, N. (2011). Comparing vowel formant normalisation procedures. York papers in linguistics, 2(11), 1-28.

Fraser, H. (2010). Cognitive theory as a tool for teaching pronunciation. In Fostering language teaching efficiency through cognitive linguistics (pp. 357-380). De Gruyter Mouton.

Haji, S. S., \& Mohammed, F. O. (2019). An Analysis of the Pronouncing of English Monophthongs by Kurdish EFL University Students (Northern Kurmanji Speakers). Humanities Journal of University of Zakho, 7(4), 515-524. 
Harrington, J., Palethorpe, S., \& Watson, C. (2000). Monophthongal vowel changes in Received Pronunciation: an acoustic analysis of the Queen's Christmas broadcasts. Journal of the International Phonetic Association, 30(1-2), 63-78.

Hubais, A. \& Pillai, S. (2010). An instrumental analysis of English vowels produced by Omanis. Journal of Modern Languages, 20(1), 1-18.

Hunter, G., \& Yarkiner, Z. (2014). Formant frequencies of British English vowels produced by native speakers of Cypriot Turkish. Proceedings of the Institute of Acoustics, 36, 452459.

Kachru, B. B. (1997). World Englishes and English-using communities. Annual Review of Applied Linguistics, 17, 66-87.

Kalaldeh, R. (2018). Acoustic analysis of Modern Standard Arabic vowels by Jordanian speakers. International Journal of Arabic-English Studies, 18(1), 23-48.

Khalil, S. (2014). Comparative study of the acoustic vowel space of Egyptian English vowels and general American English vowels. Linguistic Portfolios, 3(1), 8.

Koffi, E. (2019). An Acoustic Phonetic Analysis of the Intelligibility of Nepali-Accented English Vowels. Linguistic Portfolios, 8(1), 9.

Ladefoged, P. (2003). Phonetic data analysis: An introduction to fieldwork and instrumental techniques. Wiley-Blackwell.

Langstrof, C. (2006). Vowel change in New Zealand English-patterns and implications. PhD Dissertation. Christchurch, New Zealand: University of Canterbury.

Mahfouz, I. M. (2017). Analysis of Errors in the Transcription of Simple English Vowels (Monophthongs) by Egyptian Phonetics Students. Journal of the Faculty of Education - Alexandria University, 27(1), 273-307.

Munro, M. (1993). Productions of English vowels by native speakers of Arabic: Acoustic measurements and accentedness ratings. Language and Speech, 36, 39-66.

Pathan, M., Aldersi, Z., \& Alsout, E. (2014). Speaking in their language: An overview of major difficulties faced by the Libyan EFL learners in speaking skill. International Journal of English Language \& Translation Studies, 2(3), 96-105.

Reyes, P. Y. I. (2014). Perception and production of English vowels by Chilean learners of English: effect of auditory and visual modalities on phonetic training (Doctoral dissertation, UCL (University College London).

Ramadan, K. (2021). Acoustic similarity and perceptual similarity between Tripolitania-Libyan Arabic vowels and English vowels produced by Libyan EFL learners (Unpublished PhD dissertation). Universiti Putra Malaysia. Malaysia.

Rai, N., \& Thapa, B. (2015). A study on purposive sampling method in research. Kathmandu: Kathmandu School of Law.

Ritchie, J., Lewis, J., Nicholls, C. M., \& Ormston, R. (Eds.). (2013). Qualitative research practice: A guide for social science students and researchers. Sage.

Rosner, P. (1994). Rosner, Burton S.; Pickering. J. Brian. Vowel Perception and Production. New York: Oxford University Press.

Setyaningsih, K. P., Wijayanto, A., \& Suparno, S. (2019). English Vowels and Diphthongs Problems of Sudanese Learners. ELS Journal on Interdisciplinary Studies in Humanities, 2(4), 571-581.

Sulong, S. (2016). Malaysian English Monophthongs by Regional Malay Dialect Speakers: Convergence or Divergence?. Asiatic: IIUM Journal of English Language and Literature, 10(2). 
Syrdal, A. K., \& Gopal, H. S. (1986). A perceptual model of vowel recognition based on the auditory representation of American English vowels. The Journal of the Acoustical Society of America, 79(4), 1086-1100.

Thomas, E. R., \& Kendall, T. (2007). NORM: The Vowel Normalization and Plotting Suite. Online Resource. URL: Accessed: 17/11/2008.

Walker, R. (2010). Teaching the pronunciation of English as a lingua franca (Vol. 345). Oxford: Oxford University Press.

Watt, D., Fabricius, A., \& Kendall, T. (2010). More on vowels: Plotting and normalization. In Sociophonetics: A student's guide (pp. 107-118). Routledge.

Yang, B., \& Whalen, D. H. (2015). Perception and production of English vowels by American males and females. Australian Journal of Linguistics, 35(2), 121-141. 